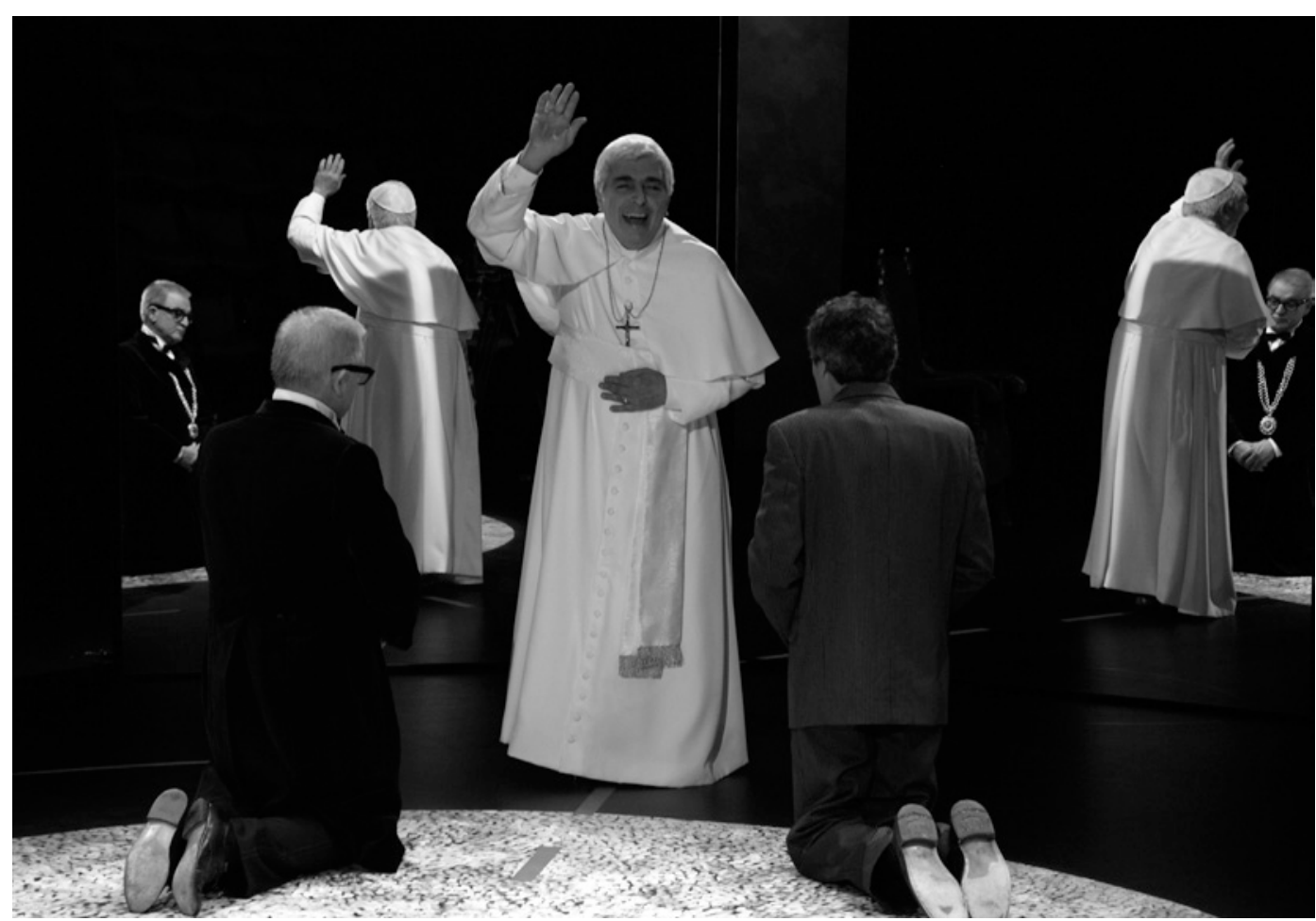

\title{
Da nossa necessidade de imagens
}

\section{Emília Costa}

Titulo: Ela (1955). Autor: Jean Genet. Tradução e encenação: Luís Miguel Cintra. Cenário e figurinos: Cristina Reis. Desenho de luz: Daniel Worm d'Assumpção. Assistente de encenação e Contra-regra: Manuel Romano. Montagem e operação de luz e som: Rui Seabra. Assistente de produção: Tânia Trigueiros. Interpretação: Dinis Gomes, Luis Lima Barreto, Luis Miguel Cintra, Ricardo Aibéo e Manuel Romano. Produção: Teatro da Cornucópia. Local e data de estreia: Teatro do Bairro Alto, Lisboa, 16 de Junho de 2011.

0 inferno, são os outros Jean-Paul Sartre (2010: 93, tradução minha)

Ela, peça póstuma de um acto e pouco conhecida de Jean Genet, monstro sagrado da dramaturgia da segunda metade do Séc. XX, foi a opção de Luis Miguel Cintra, no inicio da segunda década do Séc. XXI, nesta visitação do Teatro da Cornucópia a Genet, antes de encenar A varanda, do mesmo autor.

Ela e A varanda foram escritas no mesmo ano (1955) e abordam a mesma temática (a ilusão das imagens), porém, por opção de Genet, tiveram destinos diferentes. A primeira apenas veio a ser publicada postumamente em 1988 e a segunda foi publicada logo em 1956, sendo uma das peças de referência da dramaturgia de Genet.

Ela é, assim, uma criação mal-amada de Genet. Algo que não conseguiu destruir, mas que também não quis publicar em vida. Sem a grandiosidade de A varanda, Ela, na sua dimensão minimalista, é uma peça em si mesma perfeita, por abordar, de forma exemplar, a necessidade da humanidade em acreditar em imagens, e a hipocrisia, a impostura que toda a imagem é.

Genet teve a sensibilidade de escolher a melhor imagem para representar todas as imagens. Ela é Sua Santidade o Papa, o chefe espiritual da Igreja Católica, o ícone religioso de milhões de almas, o representante terreno de Deus e ainda o líder político e económico do Estado mais rico do mundo - o Vaticano. Ela é ainda a imagem da ambiguidade sexual. Um homem, que apenas pode ser homem pois os cânones católicos não permitem eleger mulheres como Papa, que se designa por Ela e se veste de saias.

E é esta imagem sagrada, objecto da devoção de milhões de almas, que Genet desconstrói num velhinho despudorado, sexualmente ambíguo e profundamente só. Dessa forma, o Papa, imagem de poder, transmuda-se em vitima. A imagem anulou o homem. Mas esse homem, perdido da sua essência, impedido de ser homem, apenas quer destruir a imagem que o transformou em nada e reencontrar-se com o jovem pastor que amava o nevoeiro e os abrunhos gelados. E é ao humanizar o Papa que Genet se afasta da mera sátira religiosa, construindo um profundo, complexo e inteligente tratado filosófico, numa obra justamente enquadrável no teatro do absurdo, nas palavras de Martin Esslin, que, em 1961, criou esta expressão para denominar, entre outros, o teatro de Jean Genet.

Luis Miguel Cintra compreendeu e transmitiu de forma exemplar a dimensão tragicómica da peça, quer na encenação quer na apreensão da personagem Ela, que representou.
Ela,

de Jean Genet, enc. Luis Miguel Cintra, Teatro da Cornucópia, 2011 (Luis Lima Barreto, Luis Miguel Cintra e Ricardo Aibéo), fot. Luis Santos.

Emília Costa é licenciada em Direito pela Faculdade de Direito da Universidade de Lisboa e mestranda em Estudos de Teatro na Faculdade de Letras da mesma Universidade. É autora das adaptações para teatro do livro Timbuktu de Paul Auster, levado à cena no Teatro da Trindade; e do livro $O$ jogador de Dostoievski, levado à cena no Teatro Municipal São Luiz. 


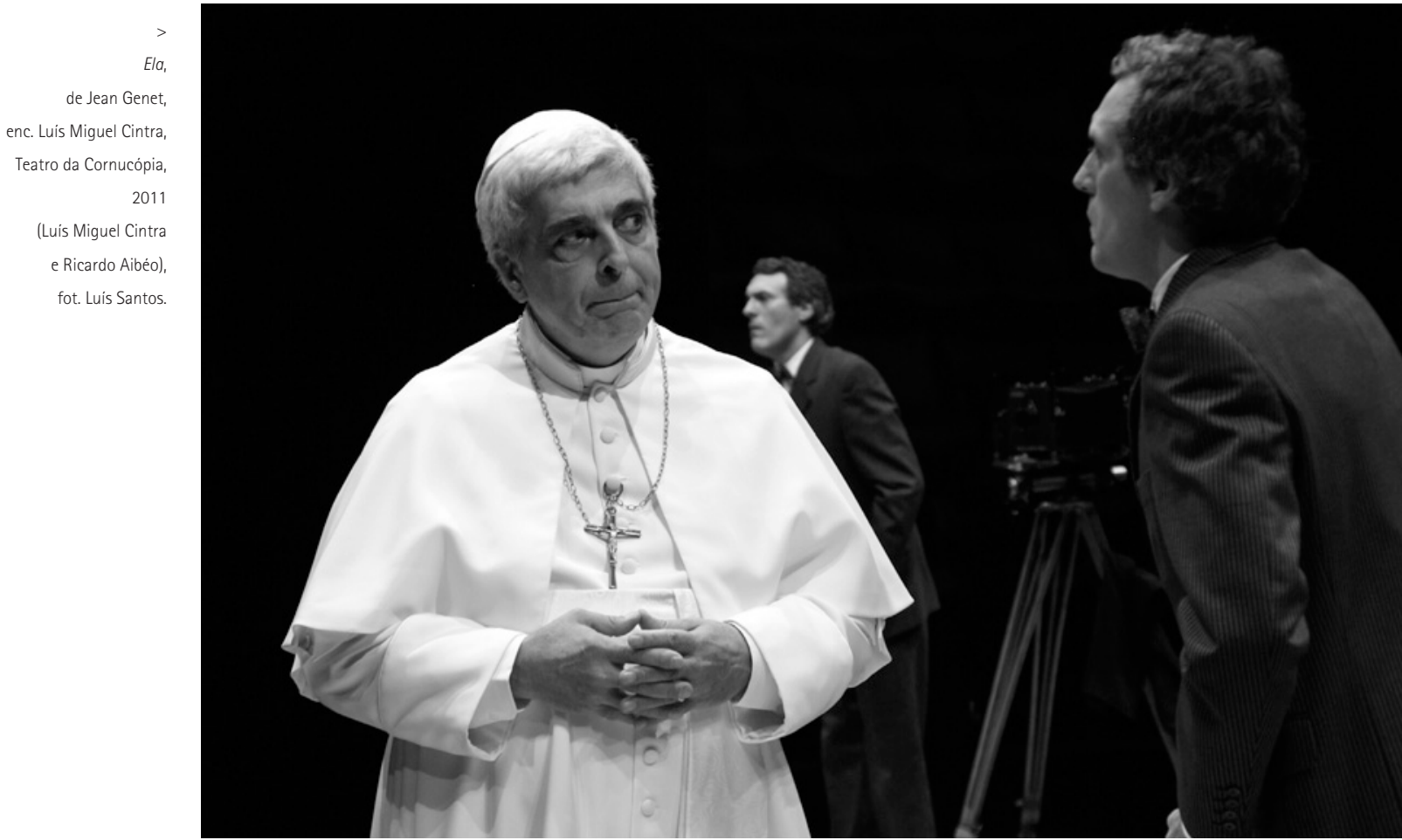

A problemática das imagens não é, aliás, nova em Cintra. Na peça Fim de citação, que levou à cena no Teatro da Cornucópia no final de 2010 (de 18/11 a 12/12), era já bem visivel a sua preocupação com a imagem, no caso, com a imagem estática e limitadora em que se encarcera o actor. Um objectivo pessoal, e explicitamente assumido no programa desse espectáculo, tem, efectivamente, marcado as últimas encenações de Cintra: afastar-se da imagem que o público criou de si, como encenador de qualidade. E com esse propósito, assinalamos os espectáculos $A$ cidade (levada à cena no Teatro Municipa São Luiz de 14/01 a 14/02) e Miserere (levado à cena no Teatro Nacional D. Maria II, de 15/04 a 23/05 de 2010).

Em Ela, Cristina Reis, cenógrafa de eleição do Teatro da Cornucópia, optou por um cenário despojado. À volta de um círculo desenhado no chão, a meio do palco e dividido por um tracejado a vermelho, foram colocados: um pequeno pedestal onde assenta uma imagem da Santa Filomena, de costas para os espectadores; uma poltrona; duas grandes molduras (ao fundo e ao centro); um par de projectores acesos, assentes num tripé; uma máquina fotográfica antiga, também assente num tripé; e uma mala. As molduras, com a chegada de Ela, transformarse-ão em espelhos. E com estes objectos, a que acrescem uma simples chávena de café e respectivo pires, um açucareiro e vários torrões de açúcar, o espectáculo cumpre-se. É dentro e fora desse círculo desenhado no chão, que tanto faz lembrar uma arena, um circo ou o mapa mundi, que os actores contracenam, ora iluminados ora escurecidos pela dança de luzes, da responsabilidade de Daniel Worm d'Assumpção.

Na primeira parte do espectáculo, o contínuo (o actor Luis Lima Barreto) e o fotógrafo (o actor Ricardo Aibéo) deambulam pelo palco, desacompanhados dos projectores de tecto que, colocados em rectângulo, passeiam a luz continuamente entre cada linha desse rectângulo, aumentando e diminuindo de intensidade, clareando e escurecendo os actores, indiferentes ao seu percurso. A luz não pára, fazendo sempre o mesmo caminho, inexoravelmente, como o tempo. E de repente a quase completa escuridão, seguida de música, e eis que entra, não Ela, mas o cardeal (o actor Dinis Gomes), vestido de vermelho e descalço. Essa figura lúbrica, quase nua por baixo da sua cappa magna, iluminada por dois projectores de tecto, ao centro, vem produzir no fotógrafo, e consequentemente, no espectador, a primeira grande sensação de estranheza, de absurdo, ao revelar o cardea como um homem lascivo, efeminado, iconoclasta. E assim somos confrontados com o nonsense, numa preparação estudada para aquilo que Ela nos trará.

Finalmente Ela chega. As molduras viram-se, dando lugar a dois grandes espelhos, colocados em diagonal, um em frente ao outro. A música é solene e um homem com cabeça de lobo (o actor Manuel Romano) anuncia "Sua Santidade". E Ela surge pelo corredor central, por entre os espectadores, às arrecuas, profusamente iluminada por vários projectores de tecto, vestida de branco, a rigor, sorrindo e acenando, na figura habitual do Papa.

E a ilusão é conseguida. É o Papa!

Com o Papa a meio do palco (e do mundo?), finda a música, e essa figura mítica transmuda-se num velhinho constipado, atrevido e saturado de tanta pose. Nele (nela?) já não existe qualquer gesto, frase, comportamento, que nos leve à veneração. Luís Miguel Cintra, neste seu Papa, impele-nos irremediavelmente ao confronto com as nossas próprias ilusões. 0 Papa é ridículo, saltita, rodopia, peidase. A pessoa atrás da imagem do Papa, não passa, por isso, de um manequim que os caçadores de imagem, os fotógrafos, manipulam a seu belo prazer, para que esse manequim se pareça com a imagem que todos achamos e exigimos ser a verdadeira. E porque o Papa nunca é visto de costas (as imagens de veneração nunca aparecem de costas), no texto de Genet, o Papa está nu na zona do cu, magistral metáfora da insignificância do homem que faz 


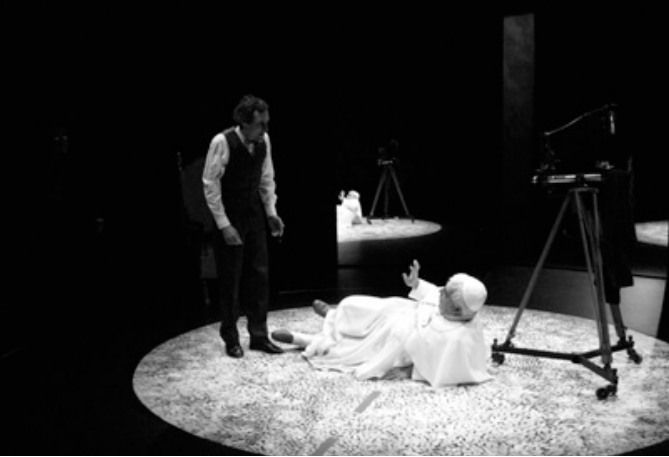

de Papa, pois, apesar do luxo que o rodeia (até o telefone é de ouro), tudo o que não é mostrado aos fiéis não merece sequer a protecção de um pano.

Luis Miguel Cintra não adoptou esta indicação cénica, nem adoptou a entrada do Papa em patins (imaginada por Genet), numa clara opção por uma encenação mais realista da própria figura do protagonista. Para Genet o teatro era pura estilização, porém, na encenação de Cintra, o objectivo foi o de aproximar o Papa da imagem que dele temos, vestindo-o a rigor e na pose que todos os Papas perfilham. E quando esse Papa, apesar do traje e da pose com que entra em cena, se transforma numa figura herética, o choque tornase mais profundo. Não vemos o cu do Papa, mas imaginamolo. E é esse Papa, que nos faz lembrar o Papa das imagens que conhecemos, quem nos relata que o momento em que está mais próximo de Deus, em que é mais pio, é quando está na posição de agachado, a cagar. Inesquecivel momento teatral e sublime representação de Cintra!

Não menos meritória é a recitação do poema sagrado em cinco cantos, Os soluços do Papa, na qual, no terceiro canto, tomamos conhecimento da bula célebre e secreta, que estabelece, regula e codifica os poderes representativos do torrão de açúcar como imagem oficial do Papa. Se de nada interessa a pessoa concreta que faz de Papa, qualquer imagem pode representá-lo. Daí que a melhor imagem para representar o Papa seja mesmo a do torrão de açúcar, pela sua brancura e pela facilidade com que se derrete. Um papa? Dois papas?

A opção final, uma vez mais, afasta-se do imaginado por Genet. Na peça Ela existe um segundo fotógrafo, em tudo semelhante ao primeiro, que, às escondidas e a mando deste último, entrou no palácio do Sumo Pontífice, para o fotografar quando estivesse a fotografar o Papa. A necessidade da imagem, parada no tempo, congelada, para dar realidade à vida, em si mesma insusceptivel de se aprisionar. Luís Miguel Cintra, jogando com os espelhos e os seus reflexos, utiliza apenas um actor (Ricardo Aibéo) para fazer dos dois fotógrafos, colocando-o a falar de e para as imagens reflectidas no espelho, onde nós, espectadores, também nos vemos reflectidos, nessa identificação com o nosso próprio labirinto de imagens, onde nos buscamos e incessantemente nos perdemos, nessa demanda interminável pela inocência perdida.

A imagem da peça é o Papa, mas podia ser a nossa imagem, enclausurados nos papéis sociais que nos atribuem, procurando adequar o nosso comportamento àquilo que imaginamos que imaginam de nós.

Condicionados pelos outros, condicionamo-nos profundamente. E é por isso que já não é o Papa a recitar os cantos quarto e quinto de Os soluços do Papa, mas sim,

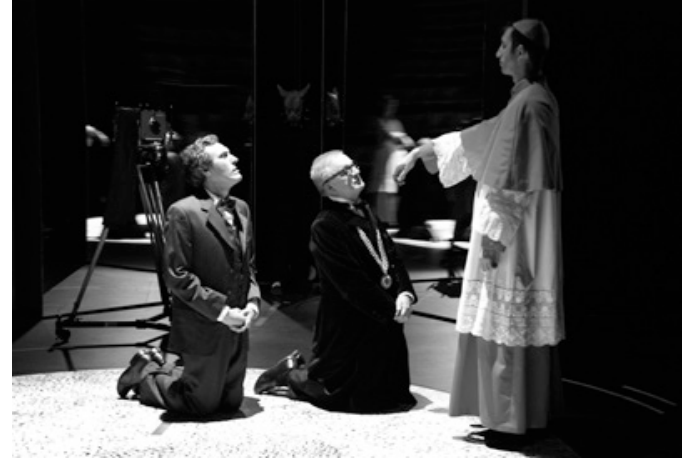

Ela,

de Jean Genet,

enc. Luis Miguel Cintra, Teatro da Cornucópia, 2011

$<$ (Ricardo Aibéo e Luis Miguel Cintra: $>$ Ricardo Aibéo, Luis Miguel Cintra e Dinis Gomes), fot. Luis Santos. o contínuo e o fotógrafo, porque todos nós somos o Papa.

A imagem da peça é o Papa, mas podia ser o próprio Genet. Três anos após a publicação do livro Saint Genet: comédien et martyr, de Jean-Paul Sartre, no qual o comportamento de Genet é escalpelizado como se ele não passasse de um objecto, um ser sem vida, fechado na imagem que Sartre dele divulgou, Genet escreveu esta peça sobre a imagem, que não deixou publicar em vida. A amizade entre Genet e Sartre ficou para sempre comprometida após a publicação de Saint Genet:comédien et martyr, tendo Genet assumido que se sentiu profundamente magoado com a forma como foi "desnudado sem complacência" (Sartre 2002: 11) por Sartre.

Porém, é sempre de imagens que se trata, e estas são insusceptíveis de apreender a essência humana, mutável, dinâmica.

Sartre atribuiu o inferno aos outros, mas é a nossa consciência dos outros, e não os outros em si mesmo, que constituem o nosso inferno. E se as imagens que temos, ou julgamos ter, nos condicionam, não é menos verdade que não sabemos estabelecer relações sociais sem construir imagens. Necessitamos de imagens, não sabemos viver sem elas, seja a imagem que temos do outro, nosso próximo, seja a imagem que temos de um qualquer símbolo. Por isso, o fim desta peça é de uma inteligência assombrosa. Depois da desconstrução do maior símbolo da igreja católica - o Papa -, depois da desconstrução dos símbolos que rodeiam essa imagem - os cardeais -, a imagem, como nós queremos e exigimos que ela seja, aparece-nos e nós submetemo-nos a ela, com o mesmo vigor, com a mesma veneração.

E assim o fotógrafo e o contínuo inclinam-se em sinal de respeito quando o cardeal, desta vez em vestes e postura adequadas, Ihes surge pela frente, e, nessa altura, o homem com cabeça de lobo (o segundo fotógrafo no texto de Genet) dispara a máquina, dá-se o flash, e é esta, e apenas esta, a imagem que ficará para a posteridade.

A contemporaneidade da peça Ela reside exactamente neste ponto. Mesmo na era da desconstrução das imagens, os fanatismos religiosos, raciais e nacionalistas continuam a proliferar, encabeçados sempre por uma imagem unificadora. Mesmo sabendo do embuste, continuamos a acreditar. É da nossa condição humana.

\section{Referências bibliográficas}

SARTRE, Jean-Paul (2002), Saint Genet ator e mártir, trad. Lucy Magalhães,

Rio de Janeiro, Petrópolis, Editora Vozes.

-- (2010), Huis clos suivi de Les mouches, Paris, Gallimard, s/n 